\title{
Synthesis of aryl-substituted thieno[3,2-b]thiophene derivatives and their use for $\mathbf{N}, \mathrm{S}$-heterotetracene construction
}

\author{
Nadezhda S. Demina ${ }^{1,2}$, Nikita A. Kazin ${ }^{1,2}$, Nikolay A. Rasputin ${ }^{1,2}$, \\ Roman A. Irgashev ${ }^{*} 1,2$ and Gennady L. Rusinov ${ }^{1,2}$
}

\author{
Full Research Paper \\ Address: \\ ${ }^{1}$ Postovsky Institute of Organic Synthesis, Ural Division, Russian \\ Academy of Sciences, S. Kovalevskoy St., 22, Ekaterinburg, 620990, \\ Russia and 2 Ural Federal University named after the first President of \\ Russia B. N. Yeltsin, Mira St., 19, Ekaterinburg, 620002, Russia \\ Email: \\ Roman A. Irgashev* - irgashev@ios.uran.ru \\ * Corresponding author \\ Keywords: \\ Fiesselmann thiophene synthesis; Fischer indole synthesis; \\ $\mathrm{N}, \mathrm{S}$-heteroacene; thieno[3,2-b]thiophene; \\ thieno[2',3':4,5]thieno[3,2-b]indole
}

\author{
Beilstein J. Org. Chem. 2019, 15, 2678-2683. \\ doi:10.3762/bjoc. 15.261 \\ Received: 26 August 2019 \\ Accepted: 31 October 2019 \\ Published: 12 November 2019 \\ Associate Editor: T. J. J. Müller \\ (C) 2019 Demina et al.; licensee Beilstein-Institut. \\ License and terms: see end of document.
}

\begin{abstract}
Fiesselmann thiophene synthesis was applied for the convenient construction of thieno[3,2-b]thiophene derivatives. Thus, new 5- or 6-aryl-3-hydroxythieno[3,2-b]thiophene-2-carboxylates were obtained by condensation of 5- or 4-aryl-3-chlorothiophene-2-carboxylates, respectively, with methyl thioglycolate in the presence of potassium tert-butoxide. The saponification of the resulting esters, with decarboxylation of the intermediating acids, gave the corresponding thieno[3,2- $b]$ thiophen-3(2H)-ones. The latter ketones were used to synthesize new N,S-heterotetracenes, namely $9 H$-thieno[2',3':4,5]thieno[3,2- $b]$ indoles by their treatment with arylhydrazines in accordance with the Fischer indolization reaction.
\end{abstract}

\section{Introduction}

The thieno[3,2-b]thiophene (TT) unit is highly demanded in modern organic synthesis since TT-based compounds have a variety of applications, e.g., in the field of organic electronics. Indeed, TT-based polymers and small molecules are used as light-harvesting dyes for dye-sensitized solar cells [1], electrondonating materials for bulk heterojunction solar cells [2-4], and p-type semiconductors for organic field-effect transistors [5-7]. Within the same context of organic semiconductor develop- ment, the bicyclic TT subunit has been used to architect various ring-fused S-heteroacenes, which have been studied extensively [8-10] due to their better characteristics compared to heteroatom-free acenes. For instance, S-heteroacenes have a better oxidation stability due to lower-lying HOMO levels, as well as more efficient charge transfer because of their tendency to $\pi$-stack, with non-bonded sulfur-sulfur interactions in the solid state, which results in large intermolecular orbital coupling of 
HOMOs and, as a consequence, enhanced carrier transport properties [10]. However, there is a problem of poor solubility of a number of S-heteroacenes, which can limit the effectiveness of semiconducting films in the case of solution-processable electronics [11]. Introducing the $\mathrm{NH}$-containing moieties, e.g., pyrrole rings, followed by attaching solubilizing substituents is one of the ways to solve this problem. Thus, different types of N,S-heteroacenes, including ones with TT-scaffold (Figure 1), which have promising electronic features, have been developed and are further investigated [12-14].

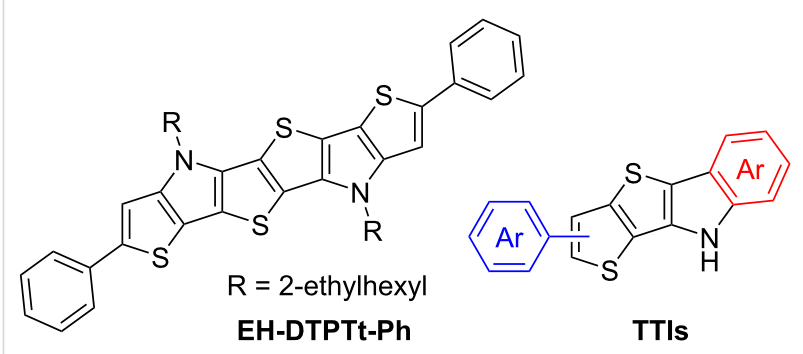

Figure 1: An example of an earlier developed S,N-heterohexacene [13] and general structure of compounds synthesized in this work.

At present, the challenge is to develop effective ways of constructing the TT-based compounds, such as S- and N,S-heteroacenes, in order to effectively tune their physical characteristics and also reduce production costs since the routine synthesis of heteroacene structures involves cross-coupling reactions catalyzed by expensive transition metals [15]. Thus, in this paper, we would like to present an efficient metal-free synthesis of the aryl-substituted TT building blocks, which can be utilized for the construction of various fused systems, including N,S-heteroacenes, e.g., substituted $9 H$-thieno[2',3':4,5]thieno[3,2- $b$ ]indoles (TTIs) (Figure 1).

\section{Results and Discussion}

Continuing our previous work in which we used the Fiesselmann thiophene synthesis [16], viz., the interaction of ethyl thioglycolate with ethyl 3-chlorobenzo[b]thiophene-2-carboxylates, to form a benzo[ $b]$ thieno[2,3- $d]$ thiophene scaffold $[17,18]$, we have decided to apply a similar approach to the synthesis of aryl-substituted TT derivatives. Thus, 3-chloro- or 3-bromothiophene-2-carboxylates bearing aryl moieties at the C-5 or C-4 position were appropriate starting substrates to construct TT scaffolds according to our strategy. Compounds $\mathbf{2 a - k}$ can be prepared either through direct palladium-catalyzed arylation of methyl 3-chlorothiophene-2-carboxylate [19] or through replacement of the amino group in the corresponding 3-aminothiophene-2-carboxylates with a halogen atom by the Sandmeyer reaction [20,21]. The former transformation is preferable for large-scale syntheses, but we failed to repeat the re- ported procedures. For example, our attempt to diazotizate methyl 3-amino-5-phenylthiophene-2-carboxylate (1a) with sodium nitrite in aqueous $\mathrm{HCl}$ or $\mathrm{HBr}$ solution failed due to the poor solubility of its hydrohalide salts, while when 3-amino ester $1 \mathrm{a}$ was treated with tert-butyl nitrite and $\mathrm{CuBr}_{2}$ in acetonitrile solution, we observed only significant decomposition of starting compound.

In this respect, we elaborated our own procedure for the preparation of aryl-substituted methyl 3-chlorothiophene-2-carboxylates $\mathbf{2}$, which consists of diazotization of the corresponding 3-aminothiophene-2-carboxylates $\mathbf{1}$ in acetonitrile solution with an aqueous sodium nitrite (1.1 equiv) solution in the presence of $p$-toluenesulfonic acid (4.0 equiv) followed by the addition of the formed solution of diazonium salts to a warm suspension of $\mathrm{CuCl}$ (5.0 equiv) in acetonitrile. Thus, compounds $\mathbf{2} \mathbf{a}-\mathbf{k}$ were obtained in 43-83\% yield (Scheme 1, see Supporting Information File 1 for more experimental details). It should be noted that the initial 3-aminoesters $\mathbf{1}$ are known compounds and can be obtained by the Fiesselmann thiophene synthesis from arylsubstituted acrylonitriles bearing a good leaving group at the C-3 position [22-24].

Methyl 3-chlorothiophene-2-carboxylates $\mathbf{2 a - k}$ were further involved in the Fiesselmann reaction with methyl thioglycolate in the presence of potassium tert-butoxide in THF, which afforded aryl-substituted methyl 3-hydroxythieno[3,2- $b]$ thiophene-2-carboxylates 3a-k in 41-78\% yields (Scheme 1). Compounds $\mathbf{3}$ were obtained in analytically pure form after single recrystallization from a toluene/ethanol mixture (1:1, $\mathrm{v} / \mathrm{v}$ ), or pure toluene for compounds $\mathbf{3 f}, \mathbf{g}, \mathbf{i}$.

Next, we performed saponification of esters $3 \mathbf{a}-\mathbf{k}$ by their treatment with an excess of sodium hydroxyde in an aqueous DMSO solution at $120^{\circ} \mathrm{C}$ for 3 hours, where the intermediating acids underwent decarboxylation to give thieno[3,2- $b$ ] thiophen-3(2H)-ones $\mathbf{4 a - k}$ after neutralization of the reaction mixture with a mineral acid. It should be noted that the obtained ketones 4 were more sensitive to the presence of acids than their benzo-annelated counterparts $[17,18]$ : when an excess of a mineral acid was used, we observed a decrease in yields of products $\mathbf{4}$ because of their partial degradation. Therefore, to neutralize the reaction mixtures, we used one equivalent of sulfuric acid relative to the alkali salt used for saponification. The resulting precipitates were then isolated by filtration, and thoroughly washed with water. As a result, we were able to isolate products in analytically pure form with yields of 93-99\% (Scheme 2).

Both compounds $\mathbf{3}$ and $\mathbf{4}$ are new functional TT-cored building blocks, which can be useful for the development of various 

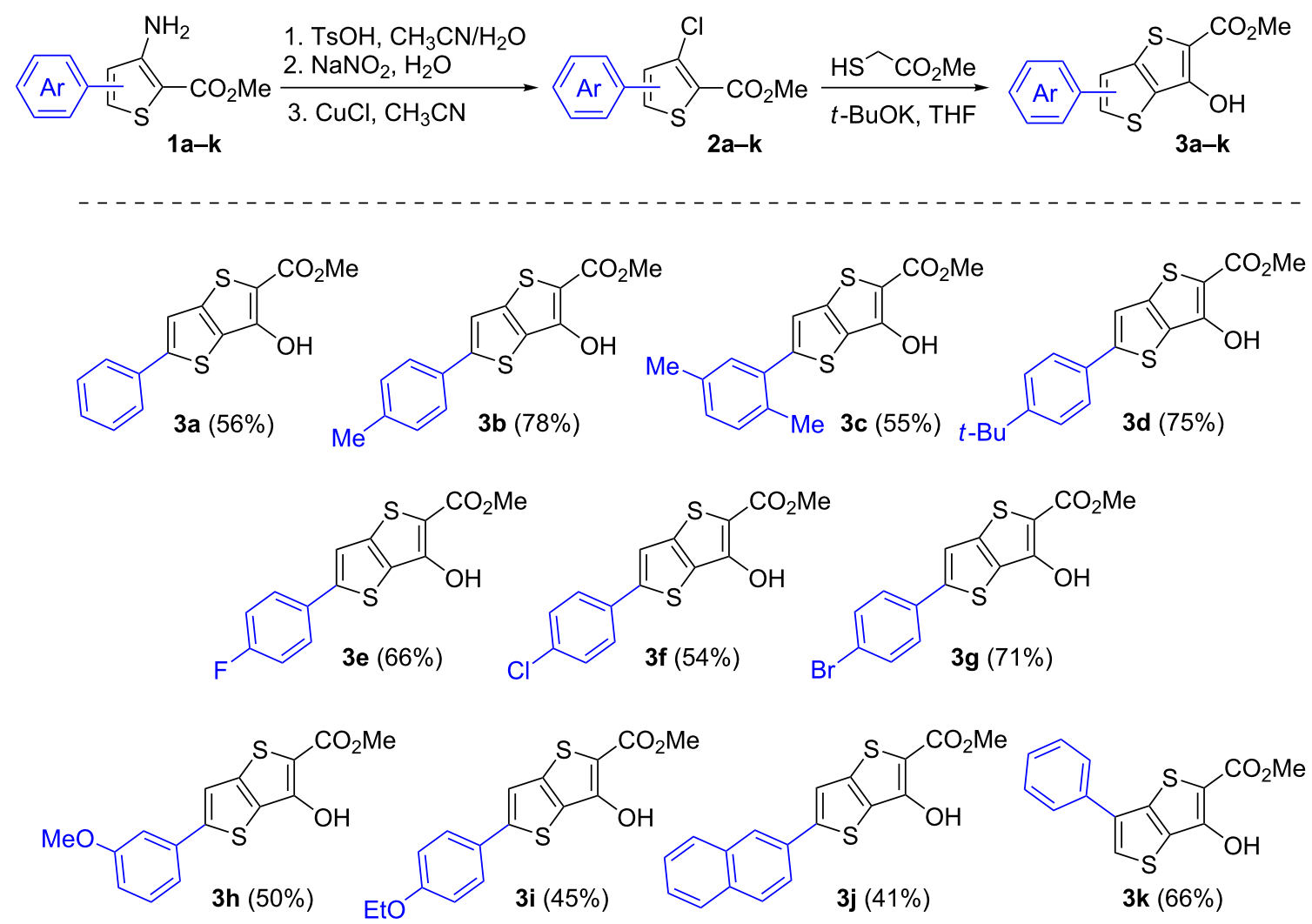

Scheme 1: Synthesis of aryl-substituted TT derivatives 3a-k, product scope, and yields.

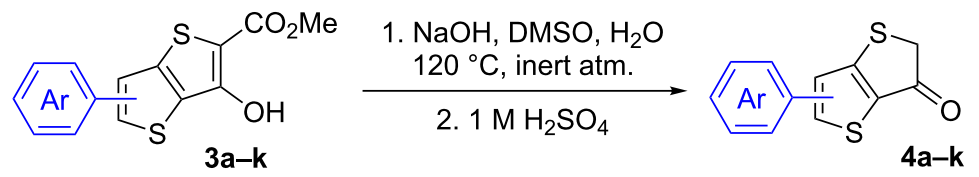<smiles>O=C1CSc2cc(-c3ccccc3)sc21</smiles><smiles>Cc1ccc(-c2cc3c(s2)C(=O)CS3)cc1</smiles><smiles>Cc1ccc(C(=O)OC(C)(C)C(=O)O)c(-c2cc(C)ccc2-c2cc3c(s2)C(=O)CS3)c1</smiles>

Me 4c $(95 \%)$ t-Bu

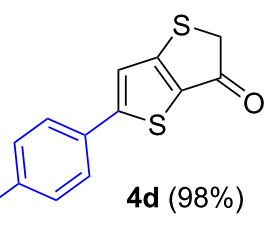<smiles>O=C1CSc2cc(-c3ccc(F)cc3)sc21</smiles><smiles>O=C1CSc2cc(-c3ccc(Cl)cc3)sc21</smiles><smiles>O=C1CSc2cc(-c3ccc(Br)cc3)sc21</smiles><smiles>COc1cccc(-c2cc3c(s2)C(=O)CS3)c1</smiles><smiles>CCOc1ccc(-c2cc3c(s2)C(=O)CS3)cc1</smiles><smiles>O=C1CSc2cc(-c3ccc4ccccc4c3)sc21</smiles><smiles>O=C1CSc2c(-c3ccccc3)csc21</smiles> 
fused molecules, e.g., we used sources $\mathbf{4}$ to construct derivatives of new TTI ring systems according to the Fischer indolization protocol [25]. To this end, compounds $\mathbf{4 a} \mathbf{a}-\mathbf{k}$ were treated with phenylhydrazine 5a in acetic acid, thus affording compounds $6 \mathbf{6}-\mathbf{k}$ in $45-83 \%$ yields (Scheme 3 ). Notably, all the indolization reactions proceeded smoothly, the formed products precipitated from hot solutions during the process, and analytically pure forms of substances were isolated by simple filtration of cooled reaction mixtures, which were diluted with methanol. In order to test the reactivity of compounds $\mathbf{4}$ and expand the range of the TTI derivatives, ketone $\mathbf{4 d}$ was similarly treated with arylhydrazines $\mathbf{5 b}$-d containing electron-acceptor substituents or electron-donor ones. There was no obvious change in the yields of compounds $\mathbf{6 1 - \mathbf { o }}$ ( $78-84 \%$, Scheme 3 ), which may indicate that the starting ketones had a rather high reactivity.

To confirm the structure of TTI derivatives $\mathbf{6}$, we attempted to grow crystals of some of these compounds, however, all of them formed powdery precipitates. Therefore, $\mathrm{N}$-functionalization of compound $\mathbf{6 d}$ was carried out with benzyl bromide in
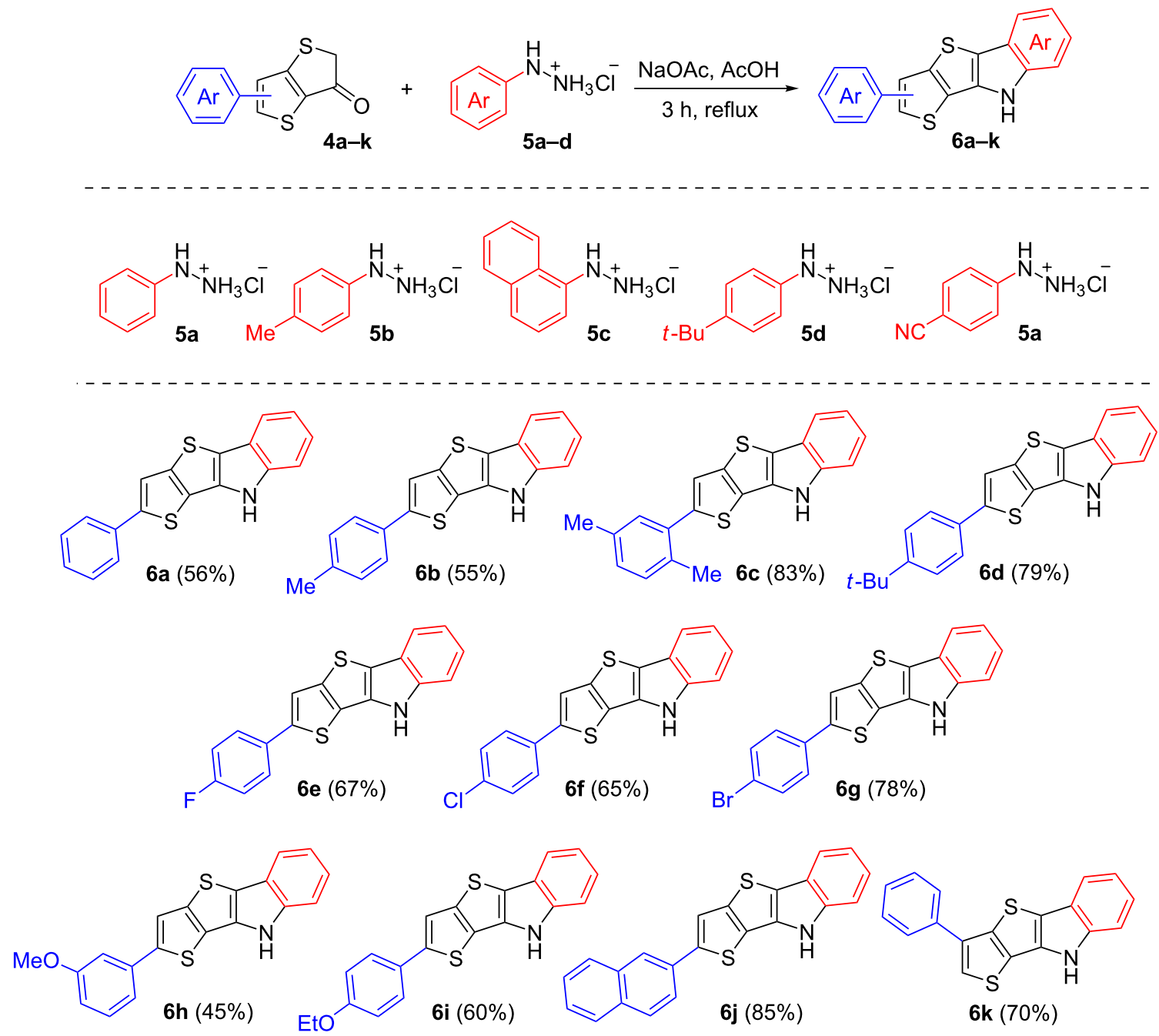<smiles></smiles> 
the presence of $\mathrm{NaH}$ (Scheme 4). The resulting benzyl derivative 7d was crystallized from ethyl acetate to give crystals, which were suitable for XRD analysis (Figure 2).

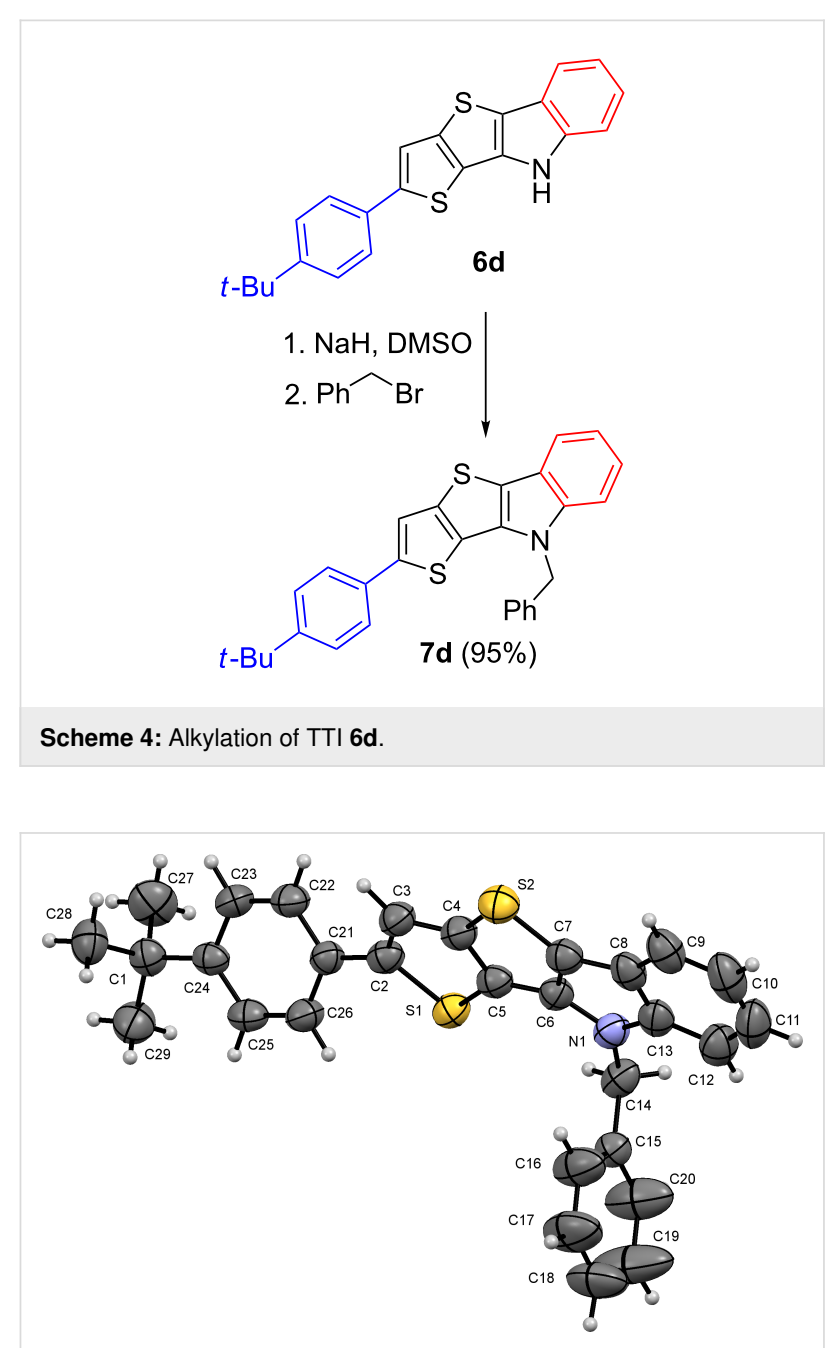

Figure 2: ORTEP diagram for the $\mathrm{X}$-ray structure of compound $\mathbf{7 d}$. Thermal ellipsoids of $50 \%$ probability are shown.

\section{Conclusion}

In summary, in this study, we showed the convenience of the Fiesselmann thiophene synthesis for the construction of new aryl-substituted thieno[3,2- $b]$ thiophene derivatives, namely the reaction of 5- or 4-aryl-3-chlorothiophene-2-carboxylates with methyl thioglycolate in the presence of base to afford 5- or 6-aryl-3-hydroxythieno[3,2-b]thiophene-2-carboxylates. The latter 3-hydroxyesters as well as the thieno[3,2-b]thiophen$3(2 \mathrm{H})$-ones prepared this way can be considered as useful synthons for the construction of various heteroacenes, which was demonstrated by the synthesis of aryl-substituted $9 H$-thieno[2',3':4,5] thieno[3,2- $b]$ indoles. These $\pi$-conjugated ring-fused molecules are of interest as electron-rich subunits for further organic semiconductors development.

\section{Supporting Information}

X-ray crystallographic data. Deposition number CCDC 1944913 for compound 7d contain the crystallographic data for these structures. These data can be obtained free of charge from the Cambridge Crystallographic Data Centre via https://www.ccdc.cam.ac.uk/data_request/cif.

\section{Supporting Information File 1}

Experimental section and copies of ${ }^{1} \mathrm{H},{ }^{13} \mathrm{C}$ and ${ }^{19} \mathrm{~F}$ NMR spectra of new compounds.

[https://www.beilstein-journals.org/bjoc/content/ supplementary/1860-5397-15-261-S1.pdf]

\section{Supporting Information File 2}

Crystal data of 7d.

[https://www.beilstein-journals.org/bjoc/content/ supplementary/1860-5397-15-261-S2.cif]

\section{Acknowledgements}

This study was supported by the Russian Foundation for Basic Research, Grant No. 18-33-20083.

\section{ORCID ${ }^{\circledR} \mathrm{iDs}$}

Nadezhda S. Demina - https://orcid.org/0000-0002-5475-134X Nikolay A. Rasputin - https://orcid.org/0000-0002-4610-3617 Roman A. Irgashev - https://orcid.org/0000-0002-8428-1748

\section{References}

1. Fernandes, S. S. M.; Belsley, M.; Pereira, A. I.; Ivanou, D.; Mendes, A.; Justino, L. L. G.; Burrows, H. D.; Raposo, M. M. M. ACS Omega 2018, 3, 12893-12904. doi:10.1021/acsomega.8b01045

2. Chen, C.-H.; Lu, Y.-J.; Su, Y.-W.; Lin, Y.-C.; Lin, H.-K.; Chen, H.-C.; Wang, H.-C.; Li, J.-X.; Wu, K.-H.; Wei, K.-H. Org. Electron. 2019, 71, 185-193. doi:10.1016/j.orgel.2019.05.002

3. Chen, J.; Wang, L.; Yang, J.; Yang, K.; Uddin, M. A.; Tang, Y.; Zhou, X.; Liao, Q.; Yu, J.; Liu, B.; Woo, H. Y.; Guo, X. Macromolecules 2019, 52, 341-353. doi:10.1021/acs.macromol.8b02360

4. Xu, Y.; Jiang, H.; Lau, T.-K.; Zhu, J.; Wang, J.; Lu, X.; Zhan, X.; Lin, Y. J. Energy Chem. 2019, 37, 58-65. doi:10.1016/j.jechem.2018.12.002

5. Yan, L.; Qi, M.; Li, A.; Meng, H.; Zhao, X.; Ali, M. U.; Xu, B. Org. Electron. 2019, 72, 1-5. doi:10.1016/j.orgel.2019.05.039

6. Tisovský, P.; Gáplovský, A.; Gmucová, K.; Novota, M.; Pavúk, M.; Weis, M. Org. Electron. 2019, 68, 121-128. doi:10.1016/j.orgel.2018.12.002

7. Wang, C.; Dong, H.; Hu, W.; Liu, Y.; Zhu, D. Chem. Rev. 2012, 112, 2208-2267. doi:10.1021/cr100380z

8. Cinar, M. E.; Ozturk, T. Chem. Rev. 2015, 115, 3036-3140. doi:10.1021/cr500271a

9. Takimiya, K.; Nakano, M.; Kang, M. J.; Miyazaki, E.; Osaka, I. Eur. J. Org. Chem. 2013, 217-227. doi:10.1002/ejoc.201201139 
10. Takimiya, K.; Shinamura, S.; Osaka, I.; Miyazaki, E. Adv. Mater. (Weinheim, Ger.) 2011, 23, 4347-4370. doi:10.1002/adma.201102007

11. Radchenko, E. S.; Anokhin, D. V.; Gerasimov, K. L.; Rodygin, A. I.; Rychkov, A. A.; Shabratova, E. D.; Grigorian, S.; Ivanov, D. A. Soft Matter 2018, 14, 2560-2566. doi:10.1039/c7sm02408h

12. Brier, E.; Wetzel, C.; Bauer, M.; Mena-Osteritz, E.; Wunderlin, M.; Bäuerle, P. Chem. Mater. 2019, 31, 7007-7023.

doi:10.1021/acs.chemmater.9b01652

13. Huang, Y.-F.; Wang, C.-K.; Lai, B.-H.; Chung, C.-L.; Chen, C.-Y.; Ciou, G.-T.; Wong, K.-T.; Wang, C.-L. ACS Appl. Mater. Interfaces 2019, 11, 21756-21765. doi:10.1021/acsami.9b04284

14. Wetzel, C.; Brier, E.; Vogt, A.; Mishra, A.; Mena-Osteritz, E.; Bäuerle, P. Angew. Chem., Int. Ed. 2015, 54, 12334-12338. doi:10.1002/anie.201502840

15. Cai, Z.; Awais, M. A.; Zhang, N.; Yu, L. Chem 2018, 4, 2538-2570. doi:10.1016/j.chempr.2018.08.017

16. Li, J. J. Name Reactions - A Collection of Detailed Mechanisms and Synthetic Applications, 5th ed.; Springer: Cham, 2014; pp 250-251. doi:10.1007/978-3-319-03979-4_104

17. Irgashev, R. A.; Demina, N. S.; Kazin, N. A.; Rusinov, G. L. Tetrahedron Lett. 2019, 60, 1135-1138. doi:10.1016/j.tetlet.2019.03.041

18. Irgashev, R. A.; Karmatsky, A. A.; Rusinov, G. L.; Charushin, V. N. Org. Lett. 2016, 18, 804-807. doi:10.1021/acs.orglett.6b00081

19. Chen, L.; Bruneau, C.; Dixneuf, P. H.; Doucet, H. Green Chem. 2012, 14, 1111-1124. doi:10.1039/c2gc16460d

20. Corral, C.; Lasso, A.; Lissaveyzky, J.; Alvarez-Insúa, A. S.; Valdeolmillos, A. M. Heterocycles 1985, 23, 1431-1435. doi:10.3987/r-1985-06-1431

21. Romagnoli, R.; Kimatrai Salvador, M.; Schiaffino Ortega, S.; Baraldi, P. G.; Oliva, P.; Baraldi, S.; Lopez-Cara, L. C.; Brancale, A.; Ferla, S.; Hamel, E.; Balzarini, J.; Liekens, S.; Mattiuzzo, E.; Basso, G.; Viola, G. Eur. J. Med. Chem. 2018, 143, 683-698. doi:10.1016/j.ejmech.2017.11.096

22. Spasov, A. A.; Chepljaeva, N. I.; Vorob'ev, E. S. Russ. J. Bioorg. Chem. 2016, 42, 133-142. doi:10.1134/s1068162016020138

23. Kim, Y.; Kim, J.; Kim, S.; Ki, Y.; Seo, S. H.; Tae, J.; Ko, M. K.; Jang, H.-S.; Lim, E. J.; Song, C.; Cho, Y.; Koh, H.-Y.; Chong, Y.; Choo, I. H.; Keum, G.; Min, S.-J.; Choo, H. Eur. J. Med. Chem. 2014, 85, 629-637. doi:10.1016/j.ejmech.2014.08.027

24. Jourdan, F.; Ladurée, D.; Robba, M. J. Heterocycl. Chem. 1994, 31 , 305-312. doi:10.1002/jhet.5570310208

25. Mundy, B. P.; Ellerd, M. G.; Favaloro, F. G., Jr.. Name Reactions and Reagents in Organic Synthesis, 2nd ed.; John Wiley \& Sons, Inc.: Hoboken, NJ, 2005; pp 253-254. doi:10.1002/9780471739876.ch1

\section{License and Terms}

This is an Open Access article under the terms of the Creative Commons Attribution License (http://creativecommons.org/licenses/by/4.0). Please note that the reuse, redistribution and reproduction in particular requires that the authors and source are credited.

The license is subject to the Beilstein Journal of Organic Chemistry terms and conditions:

(https://www.beilstein-journals.org/bjoc)

The definitive version of this article is the electronic one which can be found at:

doi:10.3762/bjoc. 15.261 